\title{
Peran Efikasi Diri, Pola Asuh Otoritatif, dan Motivasi Berprestasi terhadap Kematangan Karir
}

\author{
Triantoro Safaria ${ }^{1}$ \\ Magister Professional Psikologi \\ Universitas Ahmad Dahlan
}

\begin{abstract}
Career maturity is an important aspect that should be achieved by the individual. The low level of career maturity will result in hesitancy in deciding his career, which then would hinder the achievement of a career in the future. This study aims to test whether self-efficacy, achievement motivation, and authoritative parenting has relationship to the maturity of an individual's career. Additionally, this study also examined whether there is differences in career maturity between male and female students. A total of 214 psychology students were participated in this study. The results showed that self-efficacy, achievement motivation, and authoritative parenting contribute to students' career maturity. However, no differences was found on career maturity between male and female students. Other results found that achievement motivation has the greatest contribution to the career maturity.
\end{abstract}

Keywords: authoritative parenting, career maturity, need of achievement, self efficacy, and students

Abstrak. Kematangan karir merupakan aspek yang penting semestinya dicapai oleh individu. Tidak terbentuknya kematangan karir ini akan berakibat pada kebimbangan dalam menentukan karirnya, yang kemudian akan menghambat pencapaian karir di masa depannya. Penelitian ini bertujuan untuk menguji apakah efikasi diri, motivasi berprestasi, dan pola asuh otoritatif berperan terhadap kematangan karir individu. Selain itu menguji juga apakah ada perbedaan kematangan karir antara laki-laki dengan perempuan. Sejumlah 214 mahasiswa psikologi dilibatkan dalam penelitian ini. Hasil penelitian menunjukkan efikasi diri, motivasi berprestasi, dan pola asuh otoritatif berperan memberikan sumbangan terhadap kematangan karir mahasiswa. Namun tidak ditemukan perbedaan kematangan karir antara laki-laki dengan perempuan. Hasil lainnya menemukan bahwa motivasi berprestasi memiliki sumbangan terbesar terhadap kematangan karir.

Kata kunci: efikasi diri, kematangan karir, mahasiswa, motivasi berprestasi, dan pola asuh otoritatif

Teori perkembangan karir dari Super (1990), dan konstrak turunannya yaitu Career maturity (diterjemahkan sebagai kematangan karir) memberikan penjelasan

\footnotetext{
1 Korespondensi mengenai isi artikel ini dapat
} dilakukan melalui: triantoro.safaria@psy.uad.ac.id dasar tentang proses transisi dari sekolah menuju kerja yang pada dekade belakangan ini telah mendapatkan perhatian dari banyak peneliti (Patton \& Lokan, 2001). Selanjutnya penerapan dari kematangan karir ini terus dieksplorasi di beberapa negara (Naidoo, Bowman, \& 
Gerstein, 1998; Stead \& Watson, 1993). Kematangan karir berkaitan dengan kesiapan individu untuk membuat kesimpulan, keputusan sesuai usia, dan mampu menyesuaikan dengan tugas perkembangan karir (Savickas, 1997). Untuk itu konsep kematangan karir ini perlu dieksplorasi pada tingkat pendidikan tinggi, di kalangan mahasiswa (Powell \& Luzzo, 1998).

Penelitian Naidoo, dkk (1998) mengindentifkasikan dan menguji prediktorprediktor kematangan karir seperti usia, gender, status sosial ekonomi, etnik, locus of control dan ciri khas kerja. Pada sampel mahasiswa Afrika-Amerika hasil penelitian merekamenemukan hanya 9\% variasi dari kematangan karir dipengaruhi oleh enam prediktor di atas. Sejumlah penelitian terdahulu telah menguji berbagai prediktor dari kematangan karir. Sebagai contoh, usia ditemukan berperan terhadap kematangan karir, dimana usia lebih tua menunjukkan lebih memiliki kematangan karir. Pada studi di Australia (Patton \& Creed, 2001), Kanada (Alvi \& Khan, 1983), Afrika selatan (Watson \&Van Aarde, 1986) dan Nigeria (Achebe, 1982) menunjukkan hasil yang sama. Penelitian Powell and Luzzo (1998) tidak menemukan peran usia terhadap kematangan karir pada siswa sekolah di Amerika. Pada konteks di Indonesia, eksplorasi tentang faktor-faktor kematangan karir masih perlu dilakukan, mengingat beberapa studi terdahulu mengambil sampel siswa, dan masih sedikit yang melakukan pengujiannya pada sampel mahasiswa (El Hami, Hinduan, \& Sulastiana, 2009; Prahesty, \& Mulyana, 2013; Abidul Umam, 2015).

Bagaimana jika mahasiswa belum memiliki kematangan karir? Beberapa dampak negatif yang kemungkinan muncul antara lain; mahasiswa masih merasa bingung dengan pilihan karirnya di masa depan, mereka belum memiliki gambaran yang jelas tentang karir apa yang akan mereka tekuni di masa depan, pekerjaan apa yang mereka inginkan dan sukai, hingga belum jelasnya hubungan antara pilihan kuliah yang mereka jalani dengan karir di masa depan.

Penelitian ini menggunakan kematangan karir menjadi dua komponen, yaitu kematangan sikap karir dan kematangan pengetahuan karir. Prediktor yang digunakan dalam penelitian ini adalah gender, efikasi diri, pola asuh otoritatif, dan motivasi berprestasi. Penelitian ini berguna untuk memahami prediktor-prediktor kematangan karir yang signifikan dalam meningkatkan kematangan karir mahasiswa. Penelitian ini akan memberikan informasi tentang bagaimana meningkatkan kematangan karir mahasiswa melalui pengembangan efikasi diri, motivasi berprestasi,dan pola asuh otoritatif. Pencapaian kematangan karir yang matang pada mahasiswa akan mendorong pencapaian karir di masa depan.

\section{Kematangan karir}

Teori perkembangan karir yang dikemukakan oleh Super (1990) menggambarkan lima tahapan perkembangan karir individu, dimulai dari tahapan pertumbuhan (growth) (masa kanak-kanak), tahapan eksplorasi (exploration) (masa remaja), tahap pemantapan (establishment) (dewasa awal), tahapan mempertahankan (maintenance) (dewasa) dan tahapan pelepasan (withdrawal) (masa pensiun). Super (1990) mempostulatkan bahwa tugas-tugas vokasional tertentu dicapai dalam tiap tahap sesuai dengan sekuensi yang dapat diidentifikasi dan diprediksikan. Kematangan karir merujuk pada pengukuran yang bertujuan untuk mengukur tingkat perkembangan karir dalam dimensi afeksi dan kognitif seperti apa yang telah dicapai individu (Rojewski \& Hill, 1998). Crites 
(1995) mendefinisikan kematangan karir sebagai tingkat sejauhmana individu telah mencapai tugas-tugas perkembangan vokasional baik secara kognitif maupun sikap yang sesuai dengan tahapan perkembangan karirnya. Kematangan diasumsikan sebagai konstrak psikologis yang merefleksikan tingkat perkembangan intelektual, moral dan sosial yang memadai dan matang (Betz, 1996).

Kematangan karir ini menjelaskan kemampuan seseorang untuk sukses beradaptasi dan menyesuaikan dengan tugas-tugas perkembangan vokasionalnya (seperti mampu mensintesiskan, menspesifikan, dan mengimplementasikan pilihan karirnya) yang berproses dalam setiap tahap perkembangan karir dari eksplorasi menuju pelepasan (withdrawal). Sebagai sebuah konstrak, kematangan karir merepresentasikan seperangkat perilaku koping dan kesiapan individu untuk mengunakan perilaku tersebut dalam situasi karir yang ditemukan dalam setiap tahapan kehidupannya.

Untuk gender, mayoritas studi terdahulu menemukan perempuan lebih matang karirnya dibandingkan dengan laki-laki (Luzzo, 1995; Rojewski, Wicklein, \& Schell, 1995). Tetapi di negara seperti Afrika selatan (Watson, 1984) dan Nigeria (Achebe, 1982), laki-laki memiliki kematangan karir lebih tinggi. Studi lainnya tidak menemukan perbedaan kematangan karir antara laki-laki dan perempuan (Watson, Stead \& De Jager, 1995). Terkait dengan motivasi berprestasi, penelitian Tan (1989) menemukan perbedaan kematangan karir antara low achievers dan high achievers. Terkait dengan peran efikasi diri terhadap kematangan karir, penelitian Gushue, dkk (2006) menemukan tingkat efikasi diri keputusan karir (career decisionmaking self-efficacy) yang tinggi berkorelasi dengan konsep diri vokasional (vocational self-concept) dan keterlibatan lebih dalam aktivitas eksplorasi karir (career exploration activities). Sedang peran pola asuh orang tua terhadap kematangan karir ditegaskan oleh penelitian Pappas \& Kounenoua (2011) yang menemukan korelasi yang tinggi antara pengaruh orang tua (parental influence) dengan kemampuan pengambilan keputusan karir (career decision making ability). Penelitian Khasmohammadi, dkk (2010) juga menemukan bahwa sifat perfeksionis orang tua (parental perfectionism) berkorelasi dengan kebimbangan karir (career indecision) pada mahasiswa. Selain itu Palo dan Drobot (2010) menemukan model pengasuhan orang tua yang hangat, mendukung dan tegas berkorelasi dengan pilihan karir anak di masa depan. Hal serupa ditegaskan dalam penelitian Hargrove, Creagh dan Burgess (2002) yang menemukan kualitas hubungan dalam keluarga, orientasi tujuan keluarga, tingkat pengaturan dalam keluarga, dan sistem kendali keluarga berkorelasi dengan identitas vokasi (vocational identity) dan efikasi diri keputusan karir (career decision-making selfefficacy) pada mahasiswa.

Selain hal di atas, kematangan karir juga dipengaruhi oleh usia, etnik, ras, locus of control, status sosial ekonomi, work salience dan gender (Naidoo, 1998). Interaksi yang komplek dari faktor-faktor di atas mempengaruhi kesiapan individu dalam memenuhi tugas perkembangan karirnya. Crites (1978) mengajukan sebuah model yang membantu untuk memahami faktor-faktor dan variabel apa saja yang memengaruhi perkembangan karir individu. Beberapa faktor yang mempengaruhi perkembangan karir individu antara lain konsistensi pilihan karir, isi pilihan karir, kesadaran akan pilihan karirnya, kompetensi pilihan karir, proses pilihan karir, dan sikap pilihan karir. Crites' (1978) 
juga mengkonstrakkan lima dimensi kematangan karir yaitu keterlibatan dalam proses pemilihan karir (involvement in the choice process), kemandirian dalam pengambilan keputusan, orientasi terhadap kerja (orientation toward work), pilihan pada faktor pilihan vokasional (preference for vocational choice factors), dan konsepsi proses pilihan vokasional (conceptions of the vocational choice process).

\section{Pola Asuh Otoritatif}

Pola asuh sangat penting dalam perkembangan anak, baik secara sosial, emosi, maupun akademik. Penelitian terdahulu menunjukkan pola asuh sangat berperan dalam kehidupan anak, beserta perkembangan psikologisnya, termasuk juga perkembangan kematangan karir. Sebagai contoh, penelitian Dornbusch, dkk. (1987) menemukan pola asuh yang tidak konsisten/negatif berkorelasi dengan tingkat prestasi belajar yang rendah pada remaja. Baumrind's (1971) menjelaskan dan mengkonseptualisasikan tiga tipe pola asuh yaitu authoritative (otoritatif), authoritarian (otoriter), dan permisif. Menurutnya pola asuh otoritatif yang dicirikan dengan penerapan dukungan emosional (emotional support), penekanan pada standar perilaku tinggi, pemberian otonomi yang tepat (appropriate autonomy granting), dan komunikasi dua arah (bidirectional communication) menunjukkan pengaruh yang positif terhadap anak dan remaja dalam mengembangkan kematangannya (Baumrind, 1991; Darling \& Steinberg, 1993).

Pola asuh orang tua memiliki dua elemen penting yaitu responsivitas orang tua (parental responsiveness) dan tuntutan orang tua (parental demandingness) (Maccoby \& Martin, 1983). Responsivitas orang tua (parental warmth or supportiveness) mengacu pada sejauhmana orang tua secara sadar dalam mengembangkan dan menumbuhkan individualitas, pengaturan diri (self-regulation), dan kepercayaan diri melalui hubungan, suportif, dan persetujuan pada kebutuhan khusus dan harapan-harapan anak (Baumrind,1991). Tuntutan orang tua dilain sisi merujuk pada kontrol perilaku dimana orang tua menuntut anak untuk terintegrasi dalam keluarga, melalui tuntutan yang dewasa, supervisi, penegakkan disiplin, dan kesungguhan untuk meluruskan/mengatur perilaku menentang anak/perilaku salah anak (Baumrind, 1991).

Pola asuh otoritatif menunjukkan pola yang lebih fleksibel dan memberikan kesempatan pada anak kebebasan yang terbatas. Tetapi pola asuh otoritatif juga memberikan alasan-alasan secara hati-hati dibalik larangan yang mereka ajukan. Alasan rasional ini akan menjamin anak mengikuti aturan yang telah ditetapkan. Orang tua yang otoritatif merespoan kebutuhan dan ide-ide anak dan sering juga meminta saran dalam menentukan aturan dan keputusan dalam keluarga (Baumrind, 1991; Weiss \& Schwarz, 1996).

\section{Efikasi diri}

Efikasi diri terkait dengan keyakinan individu pada kemampuannya dalam mengorganisasi dan menyelesaikan sejumlah tindakan untuk mencapai sebuah tujuan (Bandura, 1997). Selain itu, Bandura (1982) juga menjelaskan efikasi diri sebagai keyakinan individu bahwa ia mampu untuk mengatasi kegiatan tertentu, situasi, atau aspek dari fungsi psikologis dan sosialnya sendiri. Sehingga dapat disimpulkan bahwa efikasi diri membuat individu percaya akan kemampuan yang dimilikinya dalam mengatasi masalah dan hambatan yang menghalangi mereka untuk mencapai suatu tujuan. Dengan kata lain individu percaya bahwa mereka 
mampu mencapai keinginan, cita-cita, mimpi-mimpi, dan tujuan mereka secara efektif.

Efikasi diri sangat penting dalam mendorong individu mencapai prestasi dan kesejahteraan hidupnya, Untuk itu individu membutuhkan efikasi diri ketika mereka menghadapi kesulitan, hambatan dan kegagalan. Menurut Schwarzer (1997) individu membutuhkan efikasi personal yang sehat untuk menjamin kekuatan usaha untuk berhasil. Selain itu affirmative sense of efficacy berkontribusi pada kesejahteraan psikologis dan juga pencapaian kinerja. Individu yang percaya bahwa mereka mampu menjadi penyebab suatu hal, dapat menjadi lebih aktif dan selfdetermined dalam kehidupannya (Schwarzer \& Born, 1997). Judge (1997) menilai efikasi diri sebagai sebuah tipe evaluasi diri, yang secara spesifik terkait dengan seberapa jauh individu dapat menunjukkan kinerjanya di berbagai situasi.

Efikasi diri merupakan komponen dari teori social cognitive yang dikemukakan Bandura (1997). Konstruk efikasi diri mencerminkan keyakinan diri optimis yang merujuk pada keyakinan bahwa seseorang dapat melakukan hal-hal/tugas baru atau sulit, atau mengatasi kesulitan, dalam berbagai bidang keberfungsian individu (Bandura, 1997). Jelas bahwa pandangan Bandura tentang efikasi diri berkaitan dengan penjelasan efikasi diri dalam domain tertentu, bukan sebuah bentuk keyakinan kompetensi global. Dalam penelitian ini, definisi operasional dari efikasi diri adalah mengacu pada pandangan global tentang kemampuan individu dalam mengatasi berbagai situasi dan keyakinan global individu dalam kemampuannya untuk mengatur dan melaksanakan sebuah rencana aksi yang diperlukan untuk mencapai tujuan tertentu.

Konsep efikasi diri global dirumuskan oleh Schwarzer (1992, 1998). Scholz, Gutiérrez-Doña, Sud, Schwarzer (2002) berpendapat efikasi diri global sebagai salah satu faktor sumber daya pribadi yang mengimbangi tuntutan lingkungan yang penuh tekanan. Efikasi diri global dapat didefinisikan sebagai kepercayaan global akan kemampuan individu dalam mengatasi berbagai tuntutan atau situasi. Efikasi diri global oleh karena itu, mengacu pada arti luas dan stabil tentang kompetensi pribadi dalam menangani secara efektif berbagai situasi dan tantangan (Schwarzer, 1993). Seperti yang dinyatakan sebelumnya, efikasi diri global berbeda dari efikasi diri yang dikemukakan Bandura (1977), dalam arti bahwa efikasi diri global berfokus pada kemampuan seseorang dalam mengatasi situasi umum sedangkan efikasi diri yang dikemukakan Bandura lebih bersifat domain-spesifik yang melihat kemampuan seseorang mengatasi dalam situasi tertentu. Dalam studi ini, efikasi diri global akan dikonseptualisasikan berdasarkan perspektif Schwarzer (1992). Efikasi diri global diukur secara unidimensionalitas sehingga tidak memiliki aspek atau subskala untuk mengukurnya (Scholz, dkk., 2002).

\section{Motivasi Berprestasi}

Motif berprestasi ditandai dengan dorongan dari individu untuk memperoleh kesuksesaan yang maksimal, menyukai tantangan pekerjaan, ingin menghasilkan prestasi yang tinggi dan semangat bersaing untuk menjadi yang terbaik. McClelland (1985) meneliti motif ini melalui sebuah tes yang dinamakan TAT (The Tematic Apperception Test), yaitu sebuah tes psikologi yang berisi gambar- 
gambar manusia yang sedang beraktivitas di dalam berbagai setting dan kondisi. Sebagai contoh gambar seorang pria yang sedang duduk dimeja kerjanya, di depannya ada lembaran kertas, di mejanya ada foto keluarganya, dan gambar ini bisa menimbulkan interpretasi ganda dengan melihat bahwa laki-laki itu seperti menatap foto keluarganya dan seperti berkonsentrasi pada pekerjaannya (McClelland, 1985).

Menurut McClelland (1985), motif berprestasi ini harus dikembangkan dan ditumbuhkan pada individu. Motif ini bisa ditingkatkan melalui pelatihan yang dirancangnya dengan para koleganya yang biasa disebut sebagai AMT (Achievement Motivation Training). Menurut McClelland (1985), adaempat ciri utama dari individu-individu yang memiliki $n$ Ach tinggi yaitu : 1). Mereka lebih memilih tugas-tugas yang menantang dengan risiko yang sedang (moderate risk taking). Individu dengan $n$ Achyang tinggi ini lebih memilih tugas-tugas yang mengandung risiko sedang, artinya mereka secara hatihati mengkalkulasikan berapa persen tingkat kegagalannya dan berapa persen tingkat kesuksesannya. Jika tingkat kegagalannya lebih besar, maka mereka berusaha untuk tidak menerima tugas tersebut. Mereka ini memiliki sikap yang realistis sekaligus pragmatis ketika berusaha mencapai dan memenuhi tujuan prestasinya. 2). Membutuhkan umpan balik yang segera (need for immediate feedback). Individu dengan $n$ Achyang tinggi lebih menyukai tugas-tugas yang memberikan umpan balik segera dan spesifik, sehingga mereka bisa mengukur kemajuan setiap tindakannya menuju tujuan. Pekerjaan yang disukai mereka seperti marketing yang menyediakan secara cepat hasil dari usahanya dengan kriteria yang jelas dan objektif yaitu angka penjualan produk. 3). Kepuasaan secara instrinsik dari penyelesaiaan tugas (satisfaction with accomplishments). Individu dengan $n$ Ach tinggi lebih puas akan penyelesaian tugas secara instrinsik daripada kepuasan ekstrinsik seperti uang. Mereka ini tidak berorientasi pada hadiah ekstrinsik seperti uang, dan hanya menganggap uang/bonus hanya sebagai ukuran atas prestasi kerja mereka, dan bukan tujuan utamanya (McClelland. 1985).

McClelland (1985) juga menegaskan bahwa kemajuan suatu bangsa ditentukan oleh seberapa besar motivasi berprestasi yang dimiliki oleh sebagian besar masyarakatnya. Semakin banyak suatu bangsa memiliki orang-orang dengan motivasi berprestasi yang tinggi, makaakan semakin maju bangsa tersebut. Sebut saja misalnya Jepang, Inggris, Amerika, dan Prancis yang merupakan negara-negara maju dan memiliki pengaruh bagi negaranegara lainnya.

Penelitian ini mengajukan hipotesis mayor sebagai berikut: Ada korelasi antara efikasi diri, pola asuh otoritatif, dan motivasi berprestasi, sebagai perangkat prediktor, dengan kematangan karir. Hipotesis minor: a) Ada korelasi positif antara efikasi diri dengan kematangan karir. b) Ada korelasi positif antara pola asuh otoritatif dengan kematangan karir. c) Ada korelasi positif antara motivasi berprestasi dengan kematangan karir.

\section{Metode}

\section{Desain Penelitian}

Penelitian ini menggunakan metode survey dengan pendekatan kuantitatif, yang dimaksudkan untuk menguji korelasi antara variabel efikasi diri, pola asuh otoritatif, dan motivasi berprestasi dengan kematangan karir. Penelitian 
dengan pendekatan kuantitatif akan menghasilkan gambaran umum tentang problem penelitian, keterkaitan antara variabel independen dan variabel dependen, serta pengujian hipotesis yang diajukan (Creswell, 2005).

\section{Karekteristik sampel penelitian}

Partisipan penelitian ini memiliki karakteristik sebagai berikut: a) Berjenis kelamin laki-laki dan perempuan. b) Mahasiswa psikologi semester empat Universitas Ahmad Dahlan. c) Berusia antara 19-23 tahun. Teknik sampling yang digunakan adalah purposive sampling yang diambil dari mahasiswa psikologi Universitas Ahmad Dahlan Yogyakarta. Jumlah sampel dalam penelitian ini adalah 214 mahasiswa.

\section{Analisis Data}

Untuk menguji hipotesis yang diajukan dalam penelitian ini digunakan teknik analisis data kuantitatif dengan mengunakan metode analisis regresi berganda tiga prediktor yang bertujuan untuk menguji korelasi antara efikasi diri, pola asuh otoritatif, dan motivasi berprestasi dengan kematangan karir. Komputasi analisis datanya menggunakan bantuan perangkat lunak Statistical Product and Serivice Solution (SPSS)versi 16.

\section{Pengukuran}

Alat pengumpulan data yang digunakan dalam penelitian ini adalah skala yang dimaksudkan untuk mengukur keempat variabel penelitian. Opsi jawaban dari skala penelitian di atas adalah SS (sangat sesuai), S (sesuai), TS (tidak sesuai) dan STS (sangat tidak sesuai). Sebelum digunakan untuk mengambil data penelitian, keempat skala akan diestimasi terlebih dulu validitas dan reliabilitasnya. Validitas isi dan reliabilitas konsistensi internal dari
Cronbach (Cronbach alpha) akan digunakan untuk mengestimasi alat ukur penelitian ini. Tujuannya adalah agar alat ukur yang digunakan dalam penelitian ini akurat dan dapat dipercaya (Leedy \& Ormrod, 2005; Creswell, 2005). Hasil estimasi reliabilitas skala menghasilkan koefisien reliabilitas yang tinggi. Tabel 1 menyajikan koefisien Cronbach Alpha skala dari masing masing variabel yang mengukur keempat variabel penelitian.

Tabel 1

Cronbach Alpha Skala Penelitian

\begin{tabular}{lc}
\hline Skala & Cronbach Alpha \\
\hline Kematangan karir & 0.953 \\
Efikasi diri & 0.904 \\
Motivasi berprestasi & 0.965 \\
Pola asuh otoritatif & 0.934 \\
\hline
\end{tabular}

\section{Hasil}

Hasil analisis data menunjukkan bahwa efikasi diri, motivasi berprestasi, dan pola asuh otoritatif memiliki peran terhadapkematangan karir mahasiswa. Sejumlah 90,5\% kematangan karir dapat dijelaskan oleh efikasi diri, motivasi berprestasi, dan pola asuh otoritatif. Sumbangan terbesar ditunjukkan oleh motivasi berprestasi $(\beta=0.859)$ disusul kemudian dengan efikasi diri $(\beta=0.364)$, dan yang terakhir pola asuh otoritatif $(\beta=$ 0.286). Tabel 2 menyajikan hasil analisis data yang dilakukan.

Tabel 3 menyajikan hasil analisis data yang meliputi nilai mean, deviasi standar, dan korelasi antar variabel. Berdasarkan analisis korelasi Pearson pada tabel 3, menunjukkan efikasi diri memiliki korelasi positif yang tinggi dengan kematangan karir $(r=0.925, p=0.000)$. Motivasi berprestasi memiliki korelasi positif yang tinggi dengan kematangan karir $(r=0.941$, $p=0.000)$. Pola asuh juga menunjukkan 
Tabel 2

Hasil analisis regresi tiga prediktor: kematangan karir berdasar efikasi diri, motivasi berprestasi, dan pola asuh otoritatif.

\begin{tabular}{llllll}
\hline \multicolumn{1}{c}{ Variabel } & \multicolumn{1}{c}{$B$} & \multicolumn{1}{c}{ SEB } & \multicolumn{1}{c}{$\boldsymbol{t}$} & \multicolumn{1}{c}{$p$} \\
\hline Efikasi diri & 0.828 & 0.156 & 0.364 & 5.316 & 0.000 \\
Motivasi berprestasi & 0.812 & 0.075 & 0.859 & 10.808 & 0.000 \\
Pola asuh otoritatif & 0.515 & 0.100 & 0.286 & 5.163 & 0.000 \\
\hline
\end{tabular}

Note. Adjusted $R^{2}=.905(N=81, p=.000)$.

Tabel 3

Means, Standard Deviations, and Intercorrelations pada variabel penelitian

\begin{tabular}{lcccccc}
\hline \multicolumn{1}{c}{ Variabel } & $M$ & $S D$ & 1 & 2 & 3 & 4 \\
\hline Kematangan karir & 73.2 & 13.6 & 1.000 & 0.925 & 0.941 & 0.833 \\
Efikasi diri & 30.8 & 5.9 & 0.925 & 1.000 & 0.951 & 0.895 \\
Motivasi berprestasi & 77.2 & 14.4 & 0.941 & 0.951 & 1.000 & 0.923 \\
Pola asuh otoritatif & 37.6 & 7.5 & 0.833 & 0.895 & 0.923 & 1.000 \\
\hline
\end{tabular}

${ }^{*} p<.05 .{ }^{*} p<.01^{* *}$

Tabel 4

Perbedaan Kematangan Karir berdasar Gender

\begin{tabular}{|c|c|c|c|c|c|c|c|c|c|}
\hline & \multicolumn{3}{|c|}{ Laki-laki } & \multicolumn{3}{|c|}{ Perempuan } & & \multirow[b]{2}{*}{ 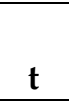 } & \multirow[b]{2}{*}{$d f$} \\
\hline & $\mathrm{M}$ & SD & $\mathrm{n}$ & $\mathrm{M}$ & SD & $\mathrm{n}$ & & & \\
\hline Kematangan karir & 75.8 & 12 & 59 & 73 & 13 & 155 & $0.26,2.969$ & 1.7 & 212 \\
\hline
\end{tabular}

${ }^{*} \mathrm{p}<.05$.

korelasi positif yang tinggi dengan kematangan karir individu $(\mathrm{r}=0.833, \mathrm{p}=$ 0.000).

Berdasarkan tabel 3 menunjukkan bahwa tidak ada perbedaan kematangan karir antara mahasiswa laki-laki dan perempuan $(\mathrm{F}=2.969, \mathrm{t}=1.7, \mathrm{p}=0.070)$.

\section{Diskusi}

Penelitian Taylor dan Betz (1983) menemukan bahwa individu yang memiliki efikasi diri rendah cenderung raguragu dalam memutuskan karir mereka di masa depan. Hal ini juga ditegaskan oleh penelitian Luzzo (1993; 1994) yang menemukan hubungan antara efikasi diri dengan kematangan karir. Hasil penelitian ini mendukung studi yang dilakukan oleh
Taylor dan Betz di atas yang menunjukkan bahwa efikasi diri merupakan prediktor dari kematangan karir.

Hal senada diungkapkan oleh Lent, Brown, dan Hackett (2002), yang mengidentifikasikan tiga variabel dominan yang memengaruhi perkembangan kematangan karir individu yaitu (1) efikasi diri, adalah keyakinan individu akan kemampuannya untuk mengorganisasikan dan menyelesaikan sebuah tugas untuk mencapai kinerja yang diinginkannya, (2) harapan hasil (outcome expectations), yaitu keyakinan individu tentang hasil yang akan didapatkannya ketika mencapai sebuah kinerja tertentu. (3) tujuan pribadi (personal goals), yaitu kemampuan individu dalam merancang tujuan yang ingin dicapainya sehingga dengan adanya tujuan iniperi- 
laku individu menjadi terarah dan memunculkan motivasi untuk mencapainya.

Mengapa efikasi diri dapat memprediksi kematangan karir? Bandura (1997) menegaskan bahwa efikasi diri mencerminkan keyakinan diri optimis yang merujuk pada keyakinan bahwa seseorang dapat melakukan hal-hal/tugas baru atau yang sulit, atau mengatasi kesulitan, dalam berbagai bidang keberfungsian individu. Individu yang memiliki efikasi diri yang tinggi cenderung akan optimis dalam menghadapi karir di masa depannya. Mereka cenderung tidak mudah menyerah, dan berani mengambil keputusan dengan keyakinan penuh. Mereka juga memiliki kecenderungan untuk berani mengeksplorasi pengetahuan karir mereka, sehingga kesiapan menghadapi karir di masa depan menjadi lebih memungkinkan. Mereka cenderung mempersiapkan segala sesuatunya untukmencapai tujuan-tujuannya. Mereka lebih banyak mengerahkan usaha-usahanya untuk memastikan tujuan di masa depannya tercapai.

Menurut Schwarzer (1997) individu membutuhkan efikasi personal yang sehat untuk menjamin kekuatan usaha untuk berhasil. Selain itu affirmative sense of efficacy berkontribusi pada pencapaian kinerja. Individu yang memiliki efikasi diri yang tinggi percaya bahwa mereka mampu menjadi penyebab suatu hal. Hal ini membuat mereka lebih aktif dalam mengeksplorasi diri dan lingkungannya, serta lebih cenderung memiliki selfdetermined dalam kehidupannya.

Hasil tambahan penelitian ini menguji peran gender terhadap kematangan karir. Hasil penelitian ini menunjukkan bahwa tidak ada perbedaan kematangan karir antara laki-laki dan perempuan. Hasil penelitian ini kontradiktif dengan hasil penelitian terdahulu yang menunjukkan ada perbedaan kematangan karir jika ditinjau dari gender, yaitu mayoritas studi terdahulu menemukan perempuan memiliki kematangan karir yang lebih tinggi daripada laki-laki (Luzzo, 1995; Rojewski, Wicklein, \& Schell, 1995). Tetapi di negara seperti Afrika selatan (Watson, 1984) and Nigeria (Achebe, 1982), laki-laki memiliki kematangan karir lebih tinggi. Studi lainnya tidak menemukan perbedaan di atas (Watson, Stead \& De Jager, 1995). Mengapa hasil penelitian ini tidak menunjukkan perbedaan? Hal ini kemungkinan terjadi dikarenakan telah meratanya kesempatan yang sama untuk mendapatkan pendidikan, dukungan, dan informasi antara laki-laki dan perempuan di Indonesia. Setiap perempuan memiliki hak dan kesempatan untuk mendapatkan pendidikan, begitu juga dengan laki-laki. Selain itu teknologi informasi seperti internet telah membuat semua informasi mudah didapatkan dalam gengaman. Baik laki-laki maupun perempuan di Indonesia memiliki kemahiran yang sama dalam mengunakan teknologi internet untuk mendapatkan pengetahuan seputar karir dan masa depan.

Terkait dengan motivasi berprestasi, penelitian Tan (1989) menemukan perbedaan antara low achievers and high achievers pada kematangan karir. Hal senada juga ditemukan oleh Luzzo (1993) yang melaporkan adanya hubungan signifikan antara nilai indeks prestasi dengan career decision-making skills. Hasil penelitian ini mendukung penelitian sebelumnya, yang mengkonfirmasikan pentingnya motivasi berprestasi bagi kematangan karir. Studi lainnya menemukan bahwa kematangan karir yang lebih tinggi ditemukan padamahasiswa dibandingkan dengan siswa (Brusoki, Golin, Gallagher, \& Moore, 1993; Hartman, Fuqua, \& Hartman, 1983). 
Mengapa motivasi berprestasi mendorong kematangan karir individu? Salah satu penjelasannya adalah individu yang memiliki motivasi berprestasi tinggi memiliki kecenderungan untuk menetapkan tujuan yang lebih tinggi.Tujuan ini kemudian mendorong mereka untuk berusaha lebih keras dengan mengerahkan segenap potensi yang mereka miliki, mencari berbagai informasi penting yang menentukan pencapaian tujuan mereka. Individu yang memiliki motivasi berprestasi yang tinggi cenderung lebih optimistik dan akan berusaha mencapai go beyond their expectations.Penjelasan inilah yang memperkuat mengapa kontribusi motivasi berprestasi terhadap kematangan karir lebih besar dibandingkan dengan sumbangan efikasi diri dan pola asuh otoritatif.

Kaitannya dengan pola asuh otoritatif, studi terdahulu menemukan bahwa pola asuh otoritatif lebih positif dalam meningkatkan kematangan anak dibandingkan penerapan pola asuh otoriter dan pola asuh permisif (Demo \& Cox, 2000). Beberapa penelitian terdahulu juga menemukan efek positif dari pola asuh otoritatif pada pencapaian akademik (Amato \& Gilbreth, 1999; Slicker, 1998; Steinberg, Dornbusch, \& Brown, 1992). Steinberg, dkk., (1989) melaporkan pola asuh otoritatif menfasilitasi prestasi sekolah (school achievement). Hasil penelitian ini mendukung penelitian sebelumnya yang menunjukkan adanya sumbangan pola asuh otoritatif pada kematangan karir individu.

Mengapa pola asuh otoritatif memberikan sumbangan terhadap kematangan karir? Penjelasannya adalah anak-anak yang dibesarkan dalam pola asuh otoritatif memiliki kesempatan dan kebebasan untuk mengekspresikan dirinya secara positif. Orang tua mereka cenderung menaruh kepercayaan yang besar kepada mereka, termasuk dalam menentukan pilihan karirnya di masa depan. Hal ini membuat anak yang dibesarkan dengan pola asuh ini mampu mengaktualisasikan dirinya secara optimal, termasuk dapat lebih optimal mengembangkan kematangan karirnya.

\section{Kesimpulan}

Penelitian ini menyimpulkan bahwa efikasi diri, motivasi berprestasi, dan pola asuh otoritatif berkontribusi terhadap kematangan karir. Motivasi berprestasi memiliki kontribusi terbesar dibandingkan dengan dua variabel lainnya terhadap kematangan karir mahasiswa. Selain itu, penelitian ini tidak menemukan perbedaan kematangan karir antara laki-laki dengan perempuan. Walaupun penelitian ini telah dilakukan sesuai dengan standar ilmiah, namun perlu diperhatikan bahwa masih terdapat kelemahan dalam penelitian ini yaitu dari sisi besarnya sampel penelitian yang kurang merepresentasikan populasi penelitiannya. Generalisasi hasil penelitian ini hanya terbatas pada mahasiswa psikologi Universitas Ahmad Dahlan khususnya semester empat. Selain itu kelemahan lainnya terletak pada estimasi validitas isi dari alat ukur penelitian ini yang hanya menggunakan satu orang professional judgment.

\section{Saran}

Saran untuk penelitian selanjutnya adalah perlu mengeksplorasi kematangan karir pada mahasiswa melalui pendekatan studi longitudinal agar mampu memastikan perubahan-perubahan yang terjadi secara lebih akurat. 


\section{Kepustakaan}

Abidul Umam, N. A. (2015) Hubungan antara self efficacy karir dengan kematangan karir siswa kelas XII SMA Negeri 1 Karanganyar Kab.Demak. Diunduh 11 April 2016 dari http://lib.unnes.ac.id.

Achebe, C. C. (1982). Assessing the vocational maturity of students in the East Central State of Nigeria. Journal of Vocational Behavior, 20, 153-161.

Alvi, S. A., \& Khan, S. B. (1983). An investigation into the construct validity of crites' career maturitymodel. Journal of Vocational Behavior, 22, 174-181.

Amato, P. R., \& Gilbreth, J. G. (1999). Nonresident fathers and children's wellbeing: A meta-analysis. Journal of Marriage and the Family, 61, 557-573. DOI: $10.2307 / 353560$.

Bandura, A. (1982). Self-efficacy mechanism in human agency. American Psychologist, 37(2), 122-147. http://dx.doi.org/ 10.1037/ 0003-066X. 37.2.122

Bandura, A. (1997). Self-efficacy: The exercise of control. New York: W. H. Freeman.

Bandura, A. (1977). Self-efficacy: Toward a unifying theory of behavioral change. Psychological Review, 84, 191-215.

Baumrind, D. (1971). Current patterns of parental authority. Developmental Psychology Monograph, 4, 1-103. doi:10.1037/h0030372.

Baumrind, D. (1991). Parenting styles and adolescent development. In R.M. Lerner, A. C. Peterson, \& J. Brooks- Gunn (Eds.), Encyclopedia of adolescence (746-758). New York: Garland Publishing, Inc.

Betz, N. E., Klein, K., \& Taylor, K. M. (1996). Evaluation of a short form of the career decision-making self effcicacy. Journal of Career Assessment, 4, 47-57.

Brusoski, G. C., Golin, A. K., Gallagher, R. P., \& Moore, M. (1993). Career group effects on career indecision, career maturity, and locus of control of undergraduate clients. Journal of Career Assessment, 1, 309-320. doi: $10.1177 / 106907279300100308$
Creswell, J.W. (2005) Educational research: Planning, conducting, and evaluating qualitaive and quantitative research (2 $2^{\text {nded). }}$ Upper Saddle River, NJ: Pearson Merrill Prentice Hall.

Crites, J. O. (1978). Theory and research handbook: career maturity inventory. Monterey, CA: CTB - MacMillan - McGraw-Hill.

Crites, J.O. (1995). Career maturity inventory. sourcebook. Ottawa, ONT: Career wave.

Darling, N., \& Steinberg, S. (1993). Parenting style as context: An integrative model. Psychological Bulletin, 113, 3, 487-496. doi: 10.1037/0033-2909.113.3.487.

Demo, D.H., \& Cox, M.J. (2000). Families with young children: A review of research in the 1990s. Journal of Marriage and the Family, 62, 867-895.

Dornbusch, S.M., Ritter, P.L., Leiderman, H., Roberts, D.F., \& Fraleigh, M.J. (1987). Child Development, 58(5), Special Issue on Schools and Development (Oct., 1987), pp. 1244-1257

El Hami, A.,Hinduan, Z., \& Sulastiana, M. (2009). Gambaran kematangan karir pada para calon sarjana di lingkungan Fakultas Psikologi Universitas Padjadjaran. Diunduh 17 April 2016, dari http://pustaka.unpad.ac.id

Gushue, G.V., Scanlan, K.R.L.,Pantzer, K.M., \& Clarke,C.P. (2006). The relationship of career decision-making self efficacy, vocational identity, and career exploration behavior in african american high school students. Journal of Career Development, 33(1), 19-28. 10.1177/0894845305283004

Hartman, B., Fuqua, D., \& Hartman, P. (1983). The construct validity of the Career Decision Scale administered to high school students. Vocational Guidance Quarterly, 31, 250-258.

Hargrove, B. K., Creagh, M. G., \& Burgess, B. L. (2002). Family interaction patterns as predictors of vocational identity and career decision-making self-efficacy. Journal of Vocational Behavior, 61(2), 185201. 
Judge, T.A. (1997). The dispositional causes of job satisfaction : A core evaluations approach. Research in Organizational Behavior, 19, 151-188

Khasmohammadi, M., Mohd Noah, S., Abdul Kadir, R.,Baba,M., Bakhash, K. F., \& Keshavarz, H.(2010). Manifestation of parental perfectionism on career indecision. Procedia Social and Behavioral Sciences, 5, 1200-1204.

Leedy, P.D \& Ormrod, J.E. (2005). Practical research : planning and design. Upper Saddle River, N.J. : Prentice Hall

Lent, R.W., Brown, S.D., \& Hackett, G. (2002). Social cognitive career theory. In D. Brown and Associates (Ed.), Career choice and development (pp. 255-311). San Fancisco, CA: Jossey-Bass.

Luzzo, D.A. (1993). Value of career decisionmaking self efficacy in predicting career decision-making attitudes and skills. Journal of Counseling Psychology, 40, 194$199 . \quad$ http://dx.doi.org/10.1037/00220167.40.2.194

Luzzo, D.A. (1994, August). Assessing the value of social-cognitive constructs in career development. Paper presented at the Annual Convention of the American Psychological Association, Los Angeles, CA.

Luzzo, D.A., \& Ward, B.E. (1995). The relative contributions of self efficacy and locus of control to the prediction of vocational congruence. Journal of Career Development, 21, 307-317.

Naidoo, A.V. (1998). Career maturity: A review of four decades of research. Bellville, South Africa: University of the Western Cape.

Naidoo, A.V., S.L. Bowman and L.H. Gerstein. (1998). Demographics, causality, work salience and the career maturity of African-American students: A causal model. Journal of Vocational Behaviour, 43, 15-27.

Maccoby, E.E., \& Martin, J.A. (1983). Socialization in the Context of the Family: Parent-Child Interaction. In P. H. Mussen, \& E. M. Hetherington (Eds.), Handbook of
Child Psychology: Vol. 4. Socialization, Personality, and Social Development (pp. 1101). New York: Wiley.

McClelland, D. C. (1985). Human motivation. Glenview, IL: Scott, Foresman.

Palo, R \& Drobot, L. (2010). The impact of family influence on the career choice of adolescents. Procedia Social and Behavioral Sciences 2, 3407-3411.

Pappas, T. S., \& Kounenoua, K. (2011). Career decision making of Greek post secondary vocational students: The impact of parents and career decision making self efficacy. Procedia Social and Behavioral Sciences, 15 (2011) 3410-3414.

Patton, W, \& Lokan, J. (2001). Perspectives on Donald Super's construct of career maturity. International Journal for Educational and Vocational Guidance, 1, 3148.

Patton, W., \& Creed, P. (2001). Developmental issues in career maturity and career decision status. The Career Development Quarterly, 49, 336-351.

Powell, D.F. \& Luzzo, D.A. (1998). Evaluating factors associated with the career maturity of high school students. The Career Development Quarterly, 47, 145-158.

Prahesty, I.D., \& Mulyana, O.P. (2013). Perbedaan kematangan karir siswa ditinjau dari jenis sekolah. Character, 2(1), 1-7.

Rojewski, J.W., \& Hill, R.B. (1998). Influence of gender and academic risk behavior on career decision making and occupational choice in early adolescence. Journal of Education for Students Placed at Risk, 3, 265287.

Rojewski, J.W., Wicklein, R.C., \& Schell, J.W. (1995). Effect of gender and academic risk behaviour on the career maturity of rural youth. Journal of Research in Rural Education, 11(2).

Savickas, M.L. (1997). Career adaptability: An integrative construct for life-span, lifespace theory. The Career Development Quarterly, 45, 247-259. 
Stead, G.B., \& Watson, M.B. (1993). How similar are the factor structures of the career decision scale, the career decision profile, and the career factors inventory? Educational and Psychological Measurement, 53, 281-290.

Steinberg, L., Elmen, J.D., \& Mounts, N.S. (1989). Authoritative parenting, psychological maturity, and academic success among adolescents. Child Development, 60, 1424-1436.

Steinberg, L., Dornbusch, S.M., \& Brown, B.B. (1992). Ethnic differences in adolescent achievement. An ecological perspective. Am Psychol. 47(6), 723-729.

Super, D.E. (1990). A life-span, life-space approach to career development. In D. Brown, \& L. Brooks (Eds.), Career choice and development: Applying contemporary theories to practice (2nd ed., pp. 197-261). San Francisco: Jossey-Bass.

Scholz, U., Gutiérrez-Doña, B., Sud, S., \& Schwarzer, R. (2002). Is general selfefficacy a universal construct? Psychometric findings from 25 countries. European Journal of Psychological Assessment, 18(3), 242-251.

Schwarzer, R. (Ed.) (1992). Self-efficacy: Thought control of action. Washington, DC: Hemisphere.

Schwarzer, R. (1997). Optimistic self-beliefs: Assessment of general perceived selfefficacy in thirteen cultures. World Psychology 3(1-2), 177-190.

Schwarzer, R., (1998). General perceived self efficacy in 14 cultures. Self efficacy assessment. February 1st; retrieved on
August 18, 2002 from http:// userpage.fuberlin.de/health /world14.htm.

Schwarzer, R., \& Born, A. (1997). Optimistic self-beliefs: Assessment of general perceived selfefficacy in thirteen cultures. World Psychology, 3(1-2), 177-190.

Slicker, E.K. (1998). Relationship of parenting style to behavioral adjustment in graduating high school seniors. Journal of Youth and Adolescence 27(3). DOI: 10. 1023/A:1022855104236

Tan, E. (1989). The career maturity of Singaporean adolescents-where do we stand and what can be done? Singapore Journal of Education, 10(2), 40-50.

Taylor, K.M., \& Betz, N.E. (1983). Applications of self efficacy theory to the understanding and treatment of career indecision. Journal of Vocational Behavior, 22 63-81.

Watson, M.B. (1984). Career development of colored high school pupils. Unpublished doctoral dissertation, University of Port Elizabeth, Port Elizabeth.

Watson, M.B., Stead, G.B., \& De Jager, A.C. (1995). The career development of black and white South African university students. International Journal for the Advancement of Counselling, 18, 39-47.

Watson, M.B., \& Van Aarde, J.A. (1986). Attitudinal career maturity of South African colored high school pupils. Journal of Vocational Behavior, 29, 7-16.

Weiss, L.H., \& Schwarz, J.C. (1996). The relationships between parenting types and older adolescents' personality, academic achievement, adjustment and substance use. Child Development, 67, 2101-2114. 